\title{
As odes de Píndaro e as tiranias siciliotas
}

\author{
ELAINE FARIAS VELOSO HIRATA
}

Museu de Arqueologia e Etnologia -

Universidade de São Paulo

\section{RESLMO}

\begin{abstract}
A s Odes de Píndaro se inserem em um conjunto de estratégias, envolvendo ações e Adiscursos, pelas quais tiranos siciliotas, como Gelão de Siracusa e Terão de Agrigento, comunicavam seus projetos políticos e buscavam o reconhecimento da comunidade colonial e do mundo grego metropolitano.
\end{abstract}

Palavras-chave: Tiranias siciliotas; Píndaro; Jogos pan-helênicos.

relação entre as odes olímpicas de Píndaro e as tiranias siciliotas é o ponto de partida
para uma reflexão sobre o significado político dos festivais - aí destacadas as competi-
ções esportivas pan-helênicas - no cenário criado com a emergência das póleis na área colonial do Ocidente grego. Nosso enfoque busca demonstrar que em tais celebrações, de marcado cunho cívico-religioso, os líderes políticos tinham a oportunidade ideal de chamar a atenção para si e para as cidades que representavam, na busca do reconhecimento e, eventualmente, da legitimação de seus projetos políticos. Assim, tiranos como Hierão de Siracusa e Terão de Agrigento potencializaram a repercussão das vitórias obtidas em jogos panhelênicos através das odes encomendadas a Píndaro, poeta lírico profundamente comprometido com os valores aristocráticos da cultura grega arcaica. Para um político de uma área periférica, que buscava tornar-se um estadista de sucesso, e para tanto priorizava projetos de conotação imperialista como o domínio da Sicília grega, a projeção pessoal em um evento que reunia todas as póleis era, sem dúvida, uma estratégia de comunicação altamente compensatória.

No entanto, para abordar esta questão é necessário que se inicie com o exame de duas problemáticas básicas.

Em primeiro lugar, avaliar como se estruturam, nesta área, as colônias gregas, levando-se em conta as razões da emigração bem como a complexidade da situação nova a ser enfrentada pelos recém-chegados em um território pouco conhecido. Não podemos esquecer 
que a Sicîlia não se apresentava aos gregos como um vazio populacional e cultural: indígenas e púnicos constituíram-se, desde os primórdios da colonização, como uma dificuldade crucial no processo de estabelecimento e expansão dos recém-chegados. As difíceis relações intercidades, que, muitas vezes, reproduziam na área colonial as constantes rivalidades das póleis de origem, representavam, assim, apenas um dos problemas a serem administrados pelos governantes. Outros focos de conflito centravam-se na hostilidade por parte das populações indígenas, com frequiência despojadas das melhores áreas de cultivo, e dos colonos púnicos, que já dominavam toda a fração ocidental da ilha mas que, certamente, sentiam como ameaça latente uma eventual expansão dos gregos em sua direção. Assim, a ocupação das novas terras configurou-se, desde o início, como um processo altamente complexo, do ponto de vista do gerenciamento de tensões sociais e políticas, por envolver variáveis em constante mutação.

Inserindo-se na problemática inicial e básica da ação colonizadora, há que se destacar agora o exame da tirania - forma de governo já definida como "endêmica" na área colonial da Magna Grécia e Sicilia. Estaremos abordando, em especial, as modalidades de comunicação, propaganda e divulgação de projetos políticos que se dirigiam aos dois principais focos de tensões sociais: 0 dêmos e a população indígena. Esta foi progressivamente deslocada de seus estabelecimentos de origem na direção do interior - território menos fértil e por vezes afastado de rotas de trocas - em razão do afluxo constante de novas levas de colonos. Os recémchegados, por sua vez, passam, em poucos anos, a engrossar um contingente de descontentes diante das parcas perspectivas de cultivo de boas terras, já ocupadas pelos primeiros colonos: os gamorói, referidos pelas fontes textuais como os que dividiram as melhores áreas na khóra siracusana. Assim, especialmente nas cidades mais povoadas, como Siracusa ou Gela, são registrados episódios indicativos de uma efervescência social gerada por esta crescente população de grupos economicamente excluídos e que serão os principais interlocutores aos quais os tiranos buscarão se dirigir, adotando diferentes formas de discursos e ações.

Tais estratégias de comunicação, por vezes similares ao que hoje conhecemos como "marketing político", faziam uso não só de festivais cívicos, como também de festas essencialmente religiosas, como as Tesmofórias, realizadas em honra de Deméter, divindade muito popular na Sicilia grega e que, presume-se, teria sido assimilada tanto aos cultos das populações indígenas, quanto púnicas (White, 1967, p. 343-352). A "manipulação" política dos cultos de Deméter e Core, por parte das tiranias siciliotas, tem sido um tema recorrente na bibliografia (White, 1964; Compernolle, 1957 e Polacco, 1986) e encontrá respaldo em várias referências textuais ${ }^{1}$ indicativas de um relacionamento estreito entre o culto das "Duas Deusas" e os assuntos políticos das colônias. (Compernolle, 1957)

\footnotetext{
1 V. especialmente: Heródoto,VII, 153, a propósito do exercício do sacerdócio das deusas ctônias pela família Dinomênida; Plutarco, Dion, 54-57 e Diodoro Sículo, 19.5.4., a respeito do "Grande Juramento", cerimônia realizada no recinto de Deméter e Core, em Siracusa, e destinada a prevenir eventuais ações de possíveis inimigos do Estado siracusano.
} 
A natureza da relação que se estabelece entre o líder político e o público a que se dirige nos parece mais complexa do que um simples mecanismo unilateral de "manipulação", reduzindo o papel da população-alvo a meros observadores e receptores de mensagens. Alguns autores vêm buscando descrever com mais precisão as nuances envolvidas nestes comportamentos e, assim, destacam a conotação interativa presente nos processos de comunicação estabelecidos entre lideranças políticas e grupos sociais específicos.

Neste sentido, W. R. Connor (1987, p. 40), ao abordar a problemática do ritual e do cerimonial na vida cívica do mundo grego de época arcaica, questiona a visão tradicional expressa, por exemplo, na obra de Martin Nilsson, Cults, myths, oracles and politics in ancient Greece (Lund, 1951), por considerá-la por demasiado centrada na explanação dos eventos em função da atuação individual dos líderes políticos. Adota, para caracterizar estes autores, a expressão "methodological individualists", emprestada de Simon Price, de quem, inclusive, cita a definição:

(...) methodological individualists can study only the organization of ritual by the elite and the exploitation of (...) ritual for propaganda purposes. That is, they draw a sharp distinction between symbolism and the "real" world of individuals and they cannot treat ritual as an articulation of collective representations. (Price, 1984, p. II)

Ao criticar a insuficiência das interpretações correntes relativas aos rituais cívicos e ao papel do líder político na condução de procedimentos de aproximação junto aos seus interlocutores obrigatórios, W. R. Connor se vale das observações de E. Muir, pautadas na situação da Veneza renascentista:

Civic rituals were commentaries on the city, its internal dynamics, and its relationship with the outside world. In commenting upon civic realities, the rituals illustrated an ideal arrangement of buman relationships, created a bomily that stimulated or altered some formal political and social ideas, and provided a medium for discourse among the constituent classes and the literate elite and the masses. Although civic rituals often served the rulers' interests they were not just propaganda and did not pass messages in only one direction. (Muir, 1981, p. 5)

A proposição do ritual cívico como um meio de comunicação em duas direções redimensiona, por sua vez, os papéis do líder e de seus seguidores, assim definidos por Connor:

The leader (...) often uses tribal structures, processions, or festivals to articulate community values and emmerging consensuses about state policy. But while be utilizes various forms of ceremony and civic religion, the distance between the leader and bis followers seems rather smaller than bas commonly been thought. The successful politician is closely linked to bis community and shares many of its values, recognizes emerging consensuses 
and knows bow to utilize familiar patterns to express and confirm new patterns of civic life; (Connor, 1987, p. 50)

The citizens are not naive bumpkins taken in by the leader's manipulation, but participants in a theatricality whose rules and roles they understand and enjoy. These are alert, even sophisticated, actors in a ritual drama affirming the establishment of a new civic order, and a renewed rapport among people, leader and protecting divinity. (Connor, 1987, p. 46)

A seguir, apresentaremos elementos indicativos de que as ações desencadeadas pelos tiranos na área colonial siciliota constituem exemplos concretos das formulações teóricas de Connor e Muir.

\section{A colonização grega no OCidente e as tiranias}

Nas palavras de Marcel Detienne, "fundar uma colônia é conceber idealmente uma cidade-estado com seus componentes essenciais, projetar um modelo abstrato de cidadania na superfície da terra, numa terra estranha. Criar na tábua rasa de um lugar, que ainda não é nem sequer um sítio". (Sissa e Detienne, 1990, p. 183)

Qual seria, no entanto, tal projeto, no caso dos colonizadores gregos do século VIII ?

Dentre as linhas de interpretação mais recentes a respeito da motivação básica para o abandono das metrópoles gregas, destacamos a que enfatiza o descontentamento de uma camada aristocrática diante da nova ordem social que se instaura na Grécia quando da emergência da póli ${ }^{2}$ e que significa basicamente o fim de seu domínio econômico, político e religioso. (Holloway, 1991, p. 47-49). A ênfase neste fator não significa que outros, como a crise de superpopulação ou os interesses comerciais, deixem de ter o seu peso dentre as razões para 0 movimento migratório. ${ }^{3}$

A sociedade aristocrática que precedeu a instituição da pólis era fundamentada economicamente na posse da terra, mantinha o controle absoluto das magistraturas e o conseqüente monopólio do exercício da justiça. A hegemonia política da aristocracia fundiária contava

${ }^{2}$ Uma definição - dentre as inúmeras que foram propostas por diferentes autores em todas as épocas - que nos parece apropriada para designar, em linhas gerais e no contexto deste trabalho, uma pólis, é sugerida por Polignac: ..."le résultat d'une mise en place progressive de cohésions et de hiérarchisations sociales sous forme d'une recherche d'ententes sur le choix de cultes médiateurs et les modalités de participation aux rites". (Polignac, 1984, p. 125)

3 Há, no entanto, algumas restrições em relação aos dois últimos argumentos: Atenas e Argos, onde parece ter havido uma explosão demográfica coincidindo com a fase inicial da colonização (Snodgrass, 1980, p. 22-23), não participaram das fundações; a Sicília, por exemplo, não possuía metais, o principal produto na mira dos mercadores, mas foi uma das áreas mais intensamente colonizada. 
com o respaldo fundamental da religião. Esta era a base ideológica de todo o sistema. As grandes familias detentoras do poder reportavam-se a antepassados heróicos, cuja memória era realimentada pelos cultos de cunho privado, mas que assumiam uma dimensão pública na medida em que tal ascendência ilustre justificava a posse do sacerdócio de importantes divindades políades. No caso específico da Sicília, é o que ocorre com o culto de Deméter, exercido pela família Dinomênida. (Compernolle, 1957)

Assim, a situação emergente vislumbrada pela sociedade aristocrática certamente significou um forte estímulo à saída da Grécia, em uma possível tentativa de recomposição da antiga ordem em um novo território. 0 mundo grego do início do século VIII testemunhava um processo lento, mas irreversivel, no sentido da substituição da autoridade e dos privilégios herdados pela instituição do poder das assembléias e das leis codificadas. A pólis grega inicia sua trajetória com toda a complexidade de situações observáveis nas diferentes regiões da Grécia. $^{4}$

As fontes escritas testemunham facetas destes momentos: Hesíodo protesta contra a antiga ordem, criticando os nobres que recebem subornos e dispensam uma justiça fraudulenta, mas Homero, em contrapartida, sugere, na Odisséia, a possibilidade de conquista de novos horizontes no oeste distante.

Teria havido uma tentativa simples de transposição de um modelo de sociedade, em vias de dissolução na Grécia, para o mundo colonial do Ocidente? Com certeza, as condições locais, em especial a pressão das populações indígenas e a constante afluência de colonos em áreas superpovoadas, desencorajaram muitas ações neste sentido.

De toda forma, o projeto de fundação de colônias, desde que conduzido por representantes deste grupo anteriormente hegemônico nas póleis de origem, possivelmente comportaria um viés nostálgico, perceptível na exacerbação de certos comportamentos e defesa de certos valores característicos de um momento histórico já superado. É o que pode ter acontecido na colônia espartana de Tarento, onde a cavalaria, a exemplo do que ocorria na cidademãe em época arcaica bem recuada, é uma instituição de feições aristocráticas claras, permanecendo privativa de camadas sociais dominantes (Wuilleumier, 1939). É também o que veremos acontecer nas Odes, em que Píndaro, em pleno século $\mathrm{V}$, reitera os valores agonísticos da ideologia aristocrática arcaica, em favor da exaltação dos tiranos siciliotas e de suas cidades.

Os aristocratas descontentes - alguns deles transformados em oikistaí - teriam organizado as empreitadas coloniais arrebanhando consigo os seus agregados e, por vezes, asso-

\footnotetext{
${ }^{4}$ A emergência da pólis no mundo grego é um fenômeno complexo que ultrapassa as interpretações que tomam o chamado "modelo ateniense" como paradigma.Veja-se, a este respeito, as oportunas observações de Claude Mossé que, ao prefaciar o livro de F. Polignac, alerta: "... Athènes n'est plus tenue pour la cité grecque par excellence, elle est une cité au destin excepcionnel, et c'est seulement parce que la réflexion politique s'est developpée à Athènes et au IVe. siècle, c'est-a-dire en un moment où grâce à l'empire qu'elle avait exercé pendant un siècle et demi, une certaine koinè institutionelle s'était peu à peu élaborée, que les anciens comme les modernes ont été tentés de l'ériger en modèle". (Polignac, 1984, p. 8)
} 
ciando-se a outros líderes, oriundos de outras regiões: é o caso, por exemplo, de Gela, fundada em 688 por contingentes de colonos ródios e cretenses.

Ora, tais composições mistas seriam focos latentes de problemas na futura colônia. A disparidade de situação sócio-econômica dos colonos, aliada à diversidade étnica, elemento gerador de um estado de beligerância constante já entre os gregos metropolitanos, acirra as tensões.

0 mundo colonial do Ocidente se apresenta, pois, como um território fértil para a eclosão de conflitoṡ trazidos das cidades-mãe, que, diante de dificuldades com certeza não previstas, serão potencializados, fugindo ao controle das lideranças originais.

A complexidade da situação da área colonial do Ocidente grego, envolvendo o contato e o confronto de comunidades politicamente autônomas, é analisada por Snodgrass sob a ótica do que ele denomina "peer polity interaction". 5 Trata-se de uma perspectiva inovadora no estudo das relações intercoloniais e, além disso, o exame das tiranias típicas da Magna Grécia, enquanto formas de controle político que ultrapassam os limites de uma cidade e buscam abranger vastas regiões, é uma contribuição original em relação à Grécia metropolitana. As considerações do autor vêm de encontro ao nosso problema específico, na medida em que consideramos o uso dos jogos pan-helênicos pelos tiranos como uma forma de comunicação e busca de legitimação de seu projeto político frente às demais cidades do mundo grego:

The western colonies, like the pan-hellenic sanctuaries (...) are a valuable testing-ground for the concept of peer polity interaction, in that they provided an area in wich the members of different Greek polities came into contact. (Snodgrass, 1991, p. 51)

De acordo com Tucídides, a tirania é uma forma de governo que surge nas cidades ricas. De fato, na Sicilia, as cidades de Siracusa e Agrigento eram das mais prósperas dentre as colônias gregas e conheceram, especialmente entre 480 e 460 a.C., momentos de grande desenvolvimento econômico e artístico, sob o governo dos tiranos Gelão, da família Dinomênida, e Terão, da família Emênida.

No caso específico da Sicília, os tiranos apresentam um componente especial: muitos são o produto de dissenções internas ocorridas nas nascentes cidades coloniais. Um episódio relatado por Heródoto $(7,153)$ é emblemático, ilustrando o relacionamento estreito que, desde os primórdios da colonização, se estabelece entre poder político, tirania e religião: Telines - antepassado dos tiranos Gelão e Hierão, da familia Dinomênida - requisitou para si mesmo e para seus descendentes o privilégio do ofício público dos cultos de Deméter em Ge-

\footnotetext{
5 Para Renfrew, "peer polity interaction designates the full range of interchanges taking place (including imitation and emulation, competition, warfare, and the exchange of material goods and of information) between autonomous (i.e. self-governing and in that sense politically independent) socio-political units which are situates deside or close to each other within a single geographical region, or in some cases more widely". (Renfrew, 1991, p. 1)
} 
la, como pagamento de um importante serviço prestado à comunidade recém-estabelecida na colônia. Sua intervenção ocorrera por ocasião de uma disputa entre dois grupos, que teria levado uma das facções envolvidas a abandonar a cidade, refugiando-se em uma região próxima, Maktorion. Por dispor Telines das "coisas sagradas" relativas ao culto da deusa e tê-las mostrado aos dissidentes, conseguiu reestabelecer a coesão da comunidade, fator primordial para a sobrevivência do novo estabelecimento. Desta feita, um culto trazido da metrópole por uma família que, de certa forma, deveria ser a sua depositária, revelou-se capaz de mediar um grave conflito social - stásis - e resolvê-lo.

Este relato é um testemunho do processo de transformação de cultos originalmente privativos de famílias importantes, na metrópole, em instituições públicas. As fontes textuais e arqueológicas comprovam a crescente difusão deste culto específico em honra de Deméter e Core, estimulado pelas tiranias da familia Dinomênida em Siracusa (Compernolle, 1957). As Tesmofórias siracusanas, por exemplo, têm seu público-alvo descaracterizado, se o compararmos ao do festival original ateniense: na metrópole, era restrito às mulheres casadas com cidadã̃os de Atenas; em Siracusa, permitia-se a participação da população em geral.

A religião, portanto, destaca-se como o elemento mediador básico e fundamental na formação das cidades no velho mundo grego e em ambiente colonial, permeando o estabelecimento das alianças, coesões, exclusões, que estão na raiz do processo de transformação do que Polignac chama de "proto-cidade" em uma verdadeira pólis. Daí reitera-se a importância dos festivais e celebrações cívico-religiosos para os líderes políticos em busca de legitimação.

Ao lado da utilização de estruturas religiosas tradicionais como elemento integrador na criação das novas cidades, vale também citar os processos de heroicização dos oikistaí como uma outra forma de promover e reconhecimento dessas fundações, em uma estratégia paralela à que, na Grécia metropolitana, está na raiz da proliferação de certas formas de cultos heróicos.

A participação vitoriosa dos tiranos nos jogos pan-helênicos ${ }^{7}$ era divulgada não apenas com os versos de Píndaro, como também através do envio de obras, encomendadas a escultores famosos, a Delfos. (Holloway, 1991, p. 100)

Também neste contexto, o conceito de "peer polity interaction" teria certamente um

\footnotetext{
${ }^{6}$ Polignac, ao analisar as fundações coloniais, propõe o conceito de "proto-cidade" para caracterizar a fase inicial do estabelecimento: "Pendant la première génération, la fondation est en réalité une "proto-cité", dejà pourvue de son territoire mais n'y ayant pas encore élaboré un corps social unifié par imbrication à divers niveaux des groupes hétérogènes qui s'y trouvent réunis. Ce sont les accords et exclusions réalisés par le biais cultuel, dont le choix et le développement des lieux de culte, qui jalonnent ensuite la mise en place d'une stabilité relationnelle". (Polignac, 1984, p. 125)

7 A valorização dos jogos pan-helênicos, revelando a alta consciência dos gregos de compartilhar "o mesmo sangue, a mesma língua, santuários e sacrifícios comuns, modos e costumes semelhantes" (Heródoto, VIII, 144), é, nas palavras de Moses Finley (1973, p. 155), "un phènomène remarquable, étant donné l'absence de toute autorité politique ou religieuse centrale; (...) le caractère surtout orale de leur culture"...
} 
campo para experimentação. Embora no âmbito de nosso estudo não seja possível o aprofundamento deste tema, vale transcrever o texto de Snodgrass, na nossa opinião uma contribuição fundamental para 0 assunto:

The Olympic festival, in particular, was clearly the place at which to make any appeal, over the beads of the individuals pólis governments, for the adoption of a pan-Hellenic policy, or more simply for recognition outside one's own polis. (...) The policies of an individual city could be held up for condemnation, as when Lysias' speech at the festival of $388 \mathrm{BC}$ provoked a riot against Dionysios, the tyrant of Syracuse, for his brutality and trachery towards fellow Greeks in the west. These examples from later history show that Greeks came to regard the great sanctuaries as offering a forum, superior to that offered by the channels of normal diplomacy, for communication with the citizens of other poleis. (Snodgrass, 1986, p. 54)

Neste contexto, inserem-se Píndaro e suas Odes. ${ }^{8}$

\section{Píndaro e a POESIa LíRICA ${ }^{9}$}

Píndaro (518/22?-438 a.C.), um dos mais famosos poetas líricos gregos, descendia de nobres espartanos (Pítica り) e manteve-se sempre fiel à sua origem aristocrática e dórica, porta-voz e ideólogo das idéias conservadoras oriundas de um tempo heróico passado, como se evidenciará no exame das suas obras.

Viveu em Atenas durante a tirania dos Pisistrátidas, aos quais provavelmente admirava; em 476 foi à Sicília a convite de Hierão I de Siracusa e lá permaneceu por alguns anos.

Píndaro, cuja fama foi grande ainda em vida, tendo sido citado por Platão e Heródoto como "clássico", desenvolveu numerosos poemas, incluindo todas as formas do lirismo coral, que compreende hinos, peanes, ditirambos, trenos, elogios, prosódias, hiporquemas, partenéias, epinícios, agrupados pelos alexandrinos em dezessete livros, de acordo com cada categoria.

As odes triunfais ou epinícios, comemorativas de vitórias nos jogos pan-helênicos olímpicos, ístmicos, píticos e nemeus - costumavam ser encomendadas pelos vencedores, sendo que as mais famosas foram dedicadas a Hierão de Siracusa e Terão de Agrigento.

0 epinício era cantado por ocasião do regresso do vencedor à sua cidade, possivelmente durante uma procissão que se encaminharia ao templo principal da cidade, onde era

\footnotetext{
${ }^{8}$ As odes escritas por Píndaro, celebrando as vitórias de Hierão de Siracusa e Terão de Agrigento, foram: Pítica II, dedicada a Hierão em 477/6 (?), como vencedor da corrida de carros; Pítica III, dedicada a Hierão de Siracusa na mesma data; Olímpica I, dedicada a Hierão de Siracusa em 476, como vencedor da corrida de cavalos; Olímpica II e III, a Terão de Agrigento, vencedor na corrida de cavalos em 476; Pítica I, a Hierão de Etna, vencedor da corrida de cavalos em 470.

9 Todos os trechos das Odes de Píndaro apresentados neste texto foram selecionados do trabalho de Daisi Malhadas (1976).
} 
consagrada a coroa de ramos de oliveira recebida como prêmio. Por vezes, as odes eram apresentadas em banquetes realizados em honra do vencedor.

A poesia de Píndaro reflete um sistema de valores assentado na noção de honra, representada na busca da vitória a partir da superação dos próprios limites, mesmo que isto significasse pôr em risco a vida. 0 termo grego agón, cuja gama de significados inclui desde a simples competição até uma ansiedade profunda, pode ser uma expressão deste sistema de valores que estava profundamente arraigado na aristocracia fundiária decadente. Píndaro, no entanto, celebrou incansavelmente tais valores, mesmo em uma época em que a cultura democrática era dominante em Atenas.

Assim, o elogio dos tiranos sempre busca, no resgate de um antepassado ilustre - mítico ou histórico - formas de legitimação do poder agora exercido. Na celebração devida a Terão, na Olímpica II, Píndaro inicia pela exaltação da vitória de sua quadriga (v. 5-6), passando, a seguir, ao elogio de seus pais:

Empenhados com toda a energia, seus pais

obtiveram a sagrada

morada à margem do rio, e da Sicília foram

os olbos; o tempo, conduzido pelo destino, os seguiu de perto acrescentando riqueza e glória

a suas ingênitas virtudes.

Píndaro, no entanto, faz remontar a Cadmo, fundador mítico de Tebas, a linhagem heróica de Terão, ao apontar como seu pai Ainesidamo, descendente de Tesandro (Olímpica II, wv. 47-52), filho de Polinice e neto de Édipo. Assim, a genealogia dos "afortunados Emênidas" (Pítica VI, v. 5), por si só, seria merecedora de cantos: "deve-se ao filho de Ainesidamo com cantos e liras elogiar" (Olímpica II, w. 50-52). Mas as vitórias nos jogos enaltecem ainda mais a imagem do tirano:

\author{
Em Olímpia, pois, ele próprio \\ o prêmio obteve: em Pito \\ e no Istmo, em comum, a ele e a seu irmão \\ igualmente, as Graças, pela vitória \\ das quadrigas na corrida de doze percursos, \\ levaram coroas (Olimpica II, w. 53-58).
}

De todas as provas, a corrida de carros - a mais onerosa - era aquela cuja vitória significava uma honra excepcional para o vencedor. Esta é, portanto, a competição preferida pelos tiranos e Píndaro reitera em suas odes o prestígio dos vencedores e a glória que advém à sua cidade: 
Agradar aos Tindáridas hospitaleiros

Estr.1

e a Helena de belas tranças,

à ilustre Acragas glorificando, prometo,

à vitória Olimpica de Terão erigindo

um bino que realça, de seus infatigáveis

cavalos, a fama. (Olímpica III, w. 1-50)

Na Olímpica I, dedicada a Hierão de Siracusa, o próprio cavalo, Ferênico, - "o que traz a vitória"- recebe menção e a expressão "rei cavaleiro" traz à lembrança os feitos heróicos de uma aristocracia guerreira sempre evocada pelas imagens que o poeta cria com o seu discurso de cunho nostálgico:

Vamos! A dórica lira do gancho

toma, se acaso de Pisa e

de Ferênico o brilbo

teu espirito subjugou às mais doces inspirações

quando, às margens do Alfeu, seu corpo se precipitou,

lançando-se na pista sem ser esporeado,

e à vitória conduziu seu dono,

de Siracusa o rei

cavaleiro. Brilha para ele a glória

36

na terra de heróis

colônia do lídio Pélope

$\mathrm{Na}$ Pítica II, dedicada à vitória de Hierão na corrida de cavalos, o poeta também exalta Siracusa:

Magna-cidade, ó Siracusa, templo de Ares,

Estr. 1

o deus de entranhas belicosas, a ti, que de homens armados

de ferro és divina nutriz,

a ti da brilhante Tebas trazendo

este canto venho, mensagem da corrida

de quadriga que sacode o solo;

nela, Hierão, dono de bons carros, saindo-se vitorioso,

com as coroas que ao longe resplandecem, cingiu Ortígia,

residência de Ártemis fluvial; não foi sem

sua ajuda que, com delicadas mãos, ele domou

os potros de rédeas multicolores

Assim, podemos afirmar, à guisa de conclusão, que as tiranias no mundo colonial do Ocidente souberam perfeitamente utilizar as ocasiões adequadas - festivais cívico-religiosos, como os jogos pan-helênicos e festividadeș em honra de uma divindade, como as Tesmofórias - para comunicar, divulgar e legitimar seus projetos políticos. Este processo teve sucesso por- 
que estabeleceu canais de comunicação com as populações a que se dirigia: para o diálogo com os representantes da aristocracia egressa da metrópole e nostálgica de um tempo heróico perdido, resgatou, através de Píndaro, alguns dos antigos valores que só a memória preservara; às populações que superpovoavam as grandes cidades, estendeu a possibilidade de participação em festividades anteriormente reservadas a poucas famílias; aos gregos das metrópoles de origem ofereceu o espetáculo das vitórias nas provas de maior prestígio, disputando, com as demais "polities" do mundo helênico, a primazia para as suas cidades.

HIRATA, E. F. V. Pindar's Odes and the Sicilian tyranies. Classica, São Paulo, v. 9/10, n. 9/10, p. 61-72, 1996/1997.

\begin{abstract}
Dindar's victory odes were commissioned by the Sicilian tyrants to integrate a whole L of acts and discourses used to communicate and to search legitimation for their political ideas or projects.
\end{abstract}

Key-words: Pindar's odes; Tyrants; Sicily. 


\section{Referências bibliográficas}

COMPERNOLLE, R. Van. Les Deinoménides et le culte de Déméter à Géla. Hommages W. Deonna, 1957, p. 474-479.

CONNOR, W. R. Tribes, festivals, and processions: civic ceremonial and political manipulation in archaic Greece. Journal of Hellanic Studies, cvii, p. 40-50, 1987.

FINLEY, M. I. Les premiers temps de la Grèce: l'âge du bronze et l'époque archaïque. 1. ed. Londres, 1970. Trad. fr. Paris, 1973.

HOLLOWAY, R. The archaeology of Ancient Sicily. Nova Iorque, 1991.

MALHADAS, D. Píndaro. Odes aos príncipes da Sicilia. Tradução com introdução e notas. UNESP, 1976.

MUIR, E. Civic ritual in Renaissance Venice. Princeton, 1981.

POLIGNAC, F. La naissance de la cité grecque. Cultes, espace et société. VIII ${ }^{\mathrm{e}}$-VII ${ }^{\mathrm{e}}$ siècles avant J.-C. Paris, 1984.

POLACCO, L. I culti di Demetra e Kore a Siracusa. Numismatica e Antichiti Classiche, Annaderni Ticinesi, XV, 1986, p. 21-37.

PRICE, S. Rituals and Power. Cambridge, 1984.

RENFREW, C. Introduction: peer polity interaction and socio-political change. In: Peer Polity interaction and Socio-political change, ed. Colin Renfrew e John F. Cherry. Cambridge, 1991.

SISSA, G. e Detienne, M. Os deuses gregos. Série “A vida cotidiana”. 1. ed. Paris, 1989. Trad. port. São Paulo, 1990.

SNODGRASS, A.M. Archaic Greece.The age of experiment. Londres, 1980.

SNODGRASS, A.M. "Interaction by design: the Greek city state". In: Peer Polity Interaction and SocioPolitical Change, ed. Colin Renfrew e John F. Cherry. Cambridge, 1991.

WHITE, D. "Demeter's Sicilian cult as a Political Instrument". Greek, Roman and Bysmniny Studies, v. 5, 1964, n. 4, p. 261 e seg.

WHITE, D. "The post-classsical cult of Malophoros at Selinus". American Journal of Archaeolity, v. 71, 1967, p.335-352.

WUILLEUMIER, P. Tarente, des origines à la conquête romaine. Paris, 1939. 